\title{
Paradise Lost em português
}

\section{Fabiano Seixas Fernandes ${ }^{*}$}

Abstract: The present article presents a comprehensive list of translations into Portuguese of English poet J ohn Milton's epic Paradise Lost, from both Portugal and Brazil. It also provides a brief account of the remainder of its lusophone translators' intellectual production (in translation or otherwise). At last, it focuses on the Brazilian prose translations by Conceição Garcia Sotto Maior and Paulo Matos Peixoto, tackling some issues inherent to the transposition of narrative poetry into prose.

Keywords: epic poetry; J ohn Milton; Paradise Lost.

Resumo: O presente artigo apresenta uma relação das traduções do poema épico Paradise Lost, do poeta inglês J ohn Milton, para o português, realizadas em Portugal e no Brasil. Também fornece um breve notícia do restante da obra tradutória e intelectual de seus tradutores lusófonos. Finalmente, enfoca as traduções brasileiras de Conceição Garcia Sotto Maior e Paulo Matos Peixoto, ambas em prosa, apontando alguns problemas inerentes à transposição de poesia narrativa em prosa.

Palavras-chave: poesia épica; J ohn Milton; Paradise Lost.

Aproximadamente um século após a publicação de Paradise Lost (1667, 2. ed, rev. 1674), obra-prima do poeta inglês John Milton, surgia a que me parece ser sua primeira tradução para o português; a esta, seguiram-se outras, em Portugal e, mais escassamente, no Brasil. 0 presente artigo corresponde à primeira etapa a ser vencida para que se possa fazer um estudo mais detalhado dessas traduções: objetiva inventariá-las e fornecer alguma notícia acerca de seus tradutores. Inicialmente, comento o método de compilação da lista. Passo, a seguir, aos tradutores: forneço a relação de suas traduções e comento as informações disponíveis acerca de cada um. No caso

\footnotetext{
*Professor adjunto da Universidade Federal do Ceará. Email: $\underline{\text { fbnfnds@gmail.com. }}$
} 
SEIXAS, F. F. Paradise Lost em português

dos tradutores brasileiros ${ }^{1}$, levanto alguns problemas pertinentes à tradução de poesia épica, comparando brevemente algumas soluções encontradas por ambos.

\section{Métodos de pesquisa}

A pesquisa pelos tradutores do épico de Milton retornou oito nomes lusófonos ${ }^{2}$ : são portugueses os três tradutores mais antigos e os três mais recentes: Padre Antônio Amaro da Silva (1789), Francisco Bento Maria Targini (1823), António J osé de Lima Leitão (1840), a dupla Fernando da Costa Soares e Raul Domingos Mateus da Silva (2002) e Jonas Daniel (2006). Dos portugueses, Targini, Lima Leitão e Daniel optam pelo verso; os demais, pela prosa $^{3}$. Quanto aos brasileiros, optaram ambos pela prosa: Conceição Garcia Sotto Maior (1946) e Paulo Matos Peixoto (1995). Não posso, infelizmente, afirmar a completude dessa lista, nem dos dados que forneço a seguir acerca de cada tradução, embora a recorrência dos dados em diversas fontes me permita relativa segurança quanto a sua correção.

A pesquisa foi levada a termo através da consulta a três tipos de bases virtuais de dados ${ }^{4}$ : primeiramente, um levantamento dessa natureza exige

\footnotetext{
${ }^{1}$ Atenho-me aos brasileiros, pois não tive acesso direto a edições impressas de todas as traduções encontradas; das traduções portuguesas, apenas a de Lima Leitão foi editada no Brasil; as demais encontram-se atualmente esgotadas mesmo em Portugal.

${ }^{2}$ Haveria ainda um nono nome. J orge Miguel BASTOS DA SILVA (2000: 114) dá ainda notícia de uma tradução por J oão Félix Pereira (1868-70); porém, nenhuma edição desta tradução consta nem das referências bibliográficas do artigo de Bastos da Silva, nem do extenso catálogo das obras de Félix Pereira oferecido pela BNP. J oão Félix Pereira tem currículo tradutório extenso, sendo sua uma das primeiras traduções da llíada para o português (1891). Traduziu ainda (e para ater-me apenas à parte clássica de seu currículo) a História de Ciro de Xenofonte (1854), As obras e os dias de Hesíodo (1876), a Jerusalém libertada de Torquato Tasso (1877), a Henriquíada de Voltaire (1878), a Eneida (1879), a Arte de amar de Ovídio (1890), as Odes Olímpicas de Píndaro (1890), a Vida de Homero por Heródoto (1891), além de fábulas de diversos países e obras pedagógicas e médicas. Mesmo assim, por não haver localizado outra notícia de sua tradução de Milton, optei por excluí-lo da presente relação.

${ }^{3}$ No caso da tradução do Padre Amaro, à qual não tive acesso direto, agradeço a Afonso Teixeira Filho - atualmente realizando estágio pós-doutoral acerca das traduções de Paradise Lost - por me informar acerca da forma de tradução.

${ }^{4}$ Todas as consultas à internet foram realizadas entre os dias 20 e 23/ago/ 2011.
} 
SEIXAS, F. F. Paradise Lost em português

consulta ao Index Translationum; as lacunas e incorreções dessa base (o leitor perceberá que não torna a ser citada no decorrer do artigo) exigem consulta a outras. Assim, não só me dirigi aos catálogos online da Biblioteca Nacional de Portugal (BNP) e da Fundação Biblioteca Nacional (FBN) do Brasil, mas também julguei pertinente lançar mãos de fontes informais, que, apesar de não terem função primordialmente científica ${ }^{5}$, por vezes, contêm maior variedade de dados que os catálogos das bibliotecas: consultei o catálogo de algumas livrarias virtuais (Livraria Cultura, Livraria Saraiva, Livros Cotovia etc.) em busca de edições ainda disponíveis, e o catálogo de um conglomerado virtual de sebos (Estante Virtual) em busca de edições já esgotadas.

Dessas pesquisas, retive, nas relações apresentadas a seguir, as edições mais antigas listadas em qualquer dos catálogos supracitados. Não posso garantir que sejam as primeiras, mesmo nos casos em que me sinto pessoalmente inclinado a acreditar que o sejam e mesmo que, por questão de brevidade, refira-me a elas como tal. No caso de edições brasileiras, realmente faltam dados que permitam traçar um histórico preciso das reedições - faltam mesmo dados acerca dos tradutores, como suas datas máximas -, embora a abundância de edições e exemplares disponíveis em sebos virtuais nos permita ter alguma noção da frequência com que foram reeditadas.

\footnotetext{
${ }^{5}$ A diferença estrita entre uma "fonte acadêmica" (e, portanto, "autorizada") e outra "não acadêmica" não me parece metodologicamente eficaz quando se está simplesmente levantando dados: nesta etapa, é válido quando se encontrar, cabendo ao pesquisador tão somente manter registro da origem dos dados. Essa distinção se torna pertinente apenas quando se analisa os dados, ou quando é necessário valorá-los ou escolher entre eles. Ainda assim, uma fonte acadêmica - embora conte com o aval prévio de uma instituição voltada à pesquisa e à produção de conhecimento - não deveria contar em todos os casos com preferência absoluta e inquestionável; o pesquisador deveria contar ao menos com alguns critérios para avaliação de seus dados. Sendo esta uma pesquisa de levantamento de dados, sirvo-me de quanto pude encontrar acerca dos tradutores e de suas traduções especialmente porque os dados parecem escassos, o que não me deixa muita escolha senão aceitar o que há. No caso das listas de obras, quando foi possível cruzar dados obtidos através de fontes distintas, não encontrei discrepâncias que tornassem necessário optar por uma fonte ou outra; mesmo assim, registro em nota de rodapé a fonte dos dados. Também me sirvo de informações advindas de páginas não acadêmicas da internet, o que não me pareceu problemático, uma vez que me limito a fornecer notícia de sua existência.
} 
SEIXAS, F. F. Paradise Lost em português

Tampouco listei as inúmeras reedições de alguns trabalhos para não estender a lista em demasiado e também porque não tenho indícios que apontem para a existência em nenhuma delas de variantes textuais: tanto a única reedição encontrada da tradução do Padre J osé Amaro da Silva quanto as inúmeras reedições brasileiras e portuguesas da de Lima Leitão são póstumas; a de Lima Leitão apresenta variedade em relação aos paratextos inúmeros especialistas são listados em diferentes edições como autores da introdução -, mas um estudo aprofundado desse tipo de recurso foge aos objetivos (e aos recursos) da presente investigação. No caso de Sotto Maior, sua tradução, publicada inicialmente nos anos 1940, foi republicada no final dos anos 1980 por outra editora, sem indícios de que haja sido retrabalhada. Não tenho indícios de reedição da tradução de Paulo Matos Peixoto, apesar do histórico editorial deste editor e tradutor ser dado a relançamentos. Finalmente, encontro apenas uma data de referência para a tradução de Daniel Jonas, e apenas o catálogo da BNP a aponta como "2a edição", sem agregar o dado de que foi "revista".

\section{Relação dos tradutores e de suas traduções ${ }^{6}$}

\section{1 Traduções portuguesas}

\subsubsection{Traduções pelo Padre J osé Amaro da SILVA (†17-- $)^{7}$}

1. 1785. GeSSNER, S. A morte de Abel: poema épico em cinco cantos. Porto: Off. que foi de António A. Ribeiro Guimarães. (Original: GeSSNER, S. [1730-88]. Der Tod Abels [1758]).

2. 1789. MILToN, J. Paraiso perdido; Paraíso restaurado (notas M. Racine e observações de M. Addison); anot. de M. Adisson sobre o Paraíso Perdido. Lisboa: Typ. Rollandiana. (Reedição 1830.) (Originais: [?] RACINE, J. [1639-99]. Comentários históricos e

\footnotetext{
${ }^{6}$ Na relação das traduções, incluo Paradise Lost para dar notícia da data de publicação da tradução, excluindo-o, porém, da relação de originais, visto que é comum a todos os tradutores aqui listados.

${ }^{7}$ Traduções atestadas pela BNP; a dos épicos de Milton também pela FBN; a tradução dos demais poemas é mencionada por BASTOS DA SILVA (2000: 114), embora essa edição não conste de sua bibliografia.
} 
SEIXAS, F. F. Paradise Lost em português

mitológicos; ADISSON, J. [1672-719]. Comentários ao Paradise Lost publicados no The spectator; MILTON, J. [1608-74]. Paradise Regain'd [1671]).

3. 1819. MILTON, J. Poemas. (Originais: "Lycidas", "L'Allegro", "II Penseroso" e "On the Morning of Christ's Nativity").

Primeiro tradutor português, parece haver poucas notícias disponíveis a respeito do Padre José Amaro da Silva - mesmo suas datas máximas são incógnitas. Do catálogo da BNP, constam apenas duas obras em seu nome precisamente, as duas primeiras traduções supracitadas. Parece plausível supor que sua intenção tradutória é pedagógica e religiosa; sua outra tradução além de Milton é outro épico de tema bíblico.

Note-se, ainda, duas peculiaridades de sua tradução de Milton: em primeiro lugar, dos tradutores listados, é o único a ter traduzido também Paradise Regain'd; também é digno de menção seu esmero em buscar paratextos adequados à compreensão dos textos traduzidos: traduz, juntamente com Paradise Lost, os comentários publicados pelo ensaísta Joseph Addison em seu The Spectator ${ }^{8}$, bem como notas explanatórias mitológicas extraídas da obra de "M. Racine" 9 .

Não encontro notícias de vasta fortuna crítica acerca do labor tradutório do Padre Amaro. A BNP dá notícia de um estudo a respeito, publicado em 1981 por Fernando de Mello Moser, parte do Congresso Histórico de Guimarães e sua Colegiada. Mais recentemente, em um trabalho acerca da recepção de Milton e Pope em Portugal - cujo enfoque é as traduções empreendidas por Targini (ver a seguir) -, José Miguel Bastos da Silva inclui uma nota na qual comenta o "prólogo do editor" da tradução do Padre Amaro,

\footnotetext{
${ }^{8}$ Addison publicou inúmeros comentários ao Paradise Lost entre dez/ 1711 e maio/1712, mais tarde compilados em livro. Devido à falta de acesso à cópia da tradução do Padre Amaro, não me foi possível verificar quais comentários exatamente foram nela incluídos.

${ }^{9}$ Gostaria de supor que o "M. Racine" citado é, de fato, o dramaturgo J ean Racine. De suas obras completas, consta a compilação das notas marginais que escreveu ao ler inúmeros clássicos greco-latinos, bem como comentários escritos à Píndaro e à Odisseia. Não me é exatamente claro se são realmente estes os comentários traduzidos pelo Padre Amaro, ou como poderiam haver sido relevantes à tradução da obra de Milton, mas são o que suas obras trazem de mais próximo; novamente, neste momento não é possível apurar com maior precisão estes dados.
} 
mostrando o cuidado daquele em distinguir Milton poeta de Milton político ${ }^{10}$, mas não se ocupa da tradução em si.

\subsubsection{Traduções por Francisco Bento Maria Targini, barão e visconde de São Lourenço (1765-827)}

1. 1819. POPE, A. Ensaio sobre o homem (trad. e notas), ed. bilíngüe, 03 vols. Londres: Offi. Typ. de C. Whittingham. (Originais: POPE, Alexander [1688-744]. Essay on Man [1734]; Messiah [1712]).

2. 1823. MILTON, J ohn. O paraíso perdido (trad. e comentários), 02 vols. Paris: Typographia de Firmino Didot.

Político português, acompanhou a família real ao Brasil, sendo aqui nomeado conselheiro do estado e da fazenda. Recebeu os títulos de barão em 1811 e de visconde em 1819. Considerado absolutista, foi impedido de desembarcar em Portugal, que se via às voltas com o liberalismo; mudou-se para Paris, onde faleceu. Em 1821, dedicou-se-Ihe desde Londres uma obra anônima, atribuída ao Padre António Vieira: A arte de furtar.

Seu labor literário não goza de grande prestígio; seu labor tradutório duas traduções pesadamente anotadas e comentadas de poemas monumentais em língua inglesa - foi recentemente apreciado por José Miguel BASTOS DA SILVA, que Ihe dedica um artigo (2000). Bastos afirma que as traduções, que poeticamente não estariam à altura de seus originais, parecem ao menos satisfatoriamente corretas do ponto de vista da expressão de seus conteúdos; menciona, porém, a preocupação de Targini em abrandar elementos

\footnotetext{
${ }^{10}$ Reproduzo a nota de BAsTos (2000: 129, nota 04): “Também os volumes de J osé Amaro da Silva vindos a lume no ano da tomada da Bastilha apresentam um 'Prologo do Editor' que, a par do elogio de Milton, contém a afirmação de que os méritos do poeta não devem confundir-se com os (de)méritos do homem público responsável por '[...] escritos amotinadores, e contrarios á devida, e imprescriptivel obediencia, que os Póvos devem, tanto por temor, como por consciencia, ter aos seus legitimos Soberanos, ainda que tyrannos sejão'. É observado ainda que 'Bem póde qualquer ser bom Poeta, e máo Politico; bom Politico, e máo Poeta. He certo que tudo devia ajudar, e concorrer para a perfeita composiçaõ do Homem; mas nem todos pódem tudo' (SILVA 1789, Vol. I, pp. iv-v)." (sic).
} 
SEIXAS, F. F. Paradise Lost em português

politicamente controversos - seja através de perífrases e eufemismos tradutórios, seja através de seus comentários e notas.

Sua análise de ambas as traduções nos leva a crer que o Ensaio sobre o homem é a mais problemática: apresentada em edição bilíngue, reproduz linha a linha o conteúdo dos versos de Pope, perdendo em alguns pontos a continuidade das ideias do poeta e desconsiderando a composição pareada do poema em heroic couplets. Ademais, suas extensas notas dão mostra de uma erudição variada e poliglota, mas, no fim das contas, pouco útil a quem é incapaz de ler as citações em diversas línguas estrangeiras. No caso específico de Milton, elogia em Targini a precisão com que verte mesmo os componentes potencialmente subversivos presentes na composição de Satã como personagem; preocupa-se também em apresentar o poema como um épico cristão, minorando o puritanismo miltoniano (afinal, Milton foi partidário do regime de Cromwell, e Paradise Lost - um épico acerca de rebeldia frustrada foi escrito após a queda deste regime, e portando da fall from grace do próprio poeta).

\subsubsection{Traduções por António J osé de Lima Leitão (1787- $856)^{11}$}

1. 1816. RACINE, J. Iphigènia: tragédia. Rio de J aneiro: Impressão Régia. (Original: RACINE, J. [1639-99]. Iphigénie [1674]).

2. 1816. Rousseau, J. As cantatas de J oão Batista Rousseau. Rio de J aneiro: na Impressão Régia. (Original: RousSEAU, J. [1670/141]. Odes, cantates, épigrammes et poésies diverses [1723]).

3. 1817. RACINE, J. Andromaca: tragédia. Bahia: Typ. de Manoel António da Silva Serva. (Original: RACINE, J. [1639-99]. Andromaque [1667]).

4. 1818. HoRÁCIO FlACO, Q. Arte poetica: epistola aos pisões, 1.ed. Bahia: Typ. de Manoel Antonio da Silva Serva, 1818. (Original:

\footnotetext{
${ }^{11}$ Traduções atestadas pela BNP; edições brasileiras esgotadas atestadas pelo catálogo da Estante Virtual. Abílio J osé Salgado menciona ainda uma outra tradução, da qual não encontro mais registros: “Em 1854 [Lima Leitão] apresenta ao editor A. J . F. Lopes (segundo nos informa Inocêncio F. da Silva), para ser impressa, uma tradução da 'Ilíada', feita directamente (sic) do grego, tal como afirma o próprio António José de Lima Leitão. Inocêncio não dá, no entanto mais informações, e afirma não saber se chegou a ser publicada" (SALGADO 2004: 944).
} 
HORÁCIO [Quintus Horatius Flaccus] [65-08 a.C. ], Ars poetica ou Epistula ad Pisones [c. 18 a.C.]).

5. 1818. VIRGílio MARÃo, P. Bucólicas; Geórgicas; Eneida (Monumento à elevação da Colonia do Brazil a Reino e ao estabelecimento do Triplice Imperio Luso) (trad. e notas), 03 vols. Rio de Janeiro: Na Typ. Real. (Originais: VIRGílıo [Publius Vergilius Maro] [70-19 a.C.]. Eclogae ou Bucolica [42-39 a.C.]; Georgica [37-30 a.C. ]; Aeneis [29-19 a.C. ]).

6. 1834. BoIleAU-DeSPRÉAUX, N. A estante do côro: poema heróicómico; M. RAYNouARD. Ode a Camões. Lisboa: na Impr. Nacional. (Originais: BoILEAU-DeSPRÉAUX, Nicolas [1636-711]. Le lutrin: poème héroï-comique [1672-83]; M. RAYNOUARD [?]. Ode a Camões [?]).

7. 1840. MILTON, J. O paraíso perdido: epopea. Lisboa: Typ. J. M. R. e Castro.

8. 1851. LUCRÉCIO CARO, T. A natureza das cousas (trad.). Typ. J orge Ferreira de Matos; Typ. A.J .F. Lopes. (Original: LUCRÉCIO [Titus Lucrecius Carus] [99-55 a.C.]. De rerum natura [01a a.C. ]).

Médico, político, homem de letras e contemporâneo de Targini e das Guerras Napoleônicas (e, portanto, do mesmo embate ideológico entre o absolutismo e o liberalismo políticos), Lima Leitão apresenta currículo tradutório conciso e vasto, com predileção por obras clássicas ou de inspiração clássica, a partir do latim e do francês. Como médico, foi pioneiro da homeopatia em Portugal e fundador da Sociedade de Ciências Médicas; como político, defensor do liberalismo, havendo atuado junto à Legião Portuguesa instituída por Napoleão (1808-14); seu histórico de traduções clássicas é também registro de sua passagem pelo Brasil, antes de ser nomeado físico-mor em Goa.

Paradise Lost é sua única tradução a partir do inglês. Das traduções portuguesas do épico, é a mais amplamente disponível no Brasil. Aqui, foi publicada como o 13ำ volume dos Clássicos Jackson, com várias reedições entre 1949 e 1970; também conheceu edições pelas editoras Edigraf (em dois tomos), Logos e Santos \& Vieira ${ }^{12}$; atualmente, encontra-se disponível em edição capa dura ilustrada pela Editora Vila Rica (1994) e em edição de bolso pela útil e duvidosa Martin Claret (2002). Costuma-se acoplá-la às ilustrações

\footnotetext{
${ }^{12}$ Edições atestadas pelo catálogo da Estante Virtual; os livreiros que vendiam as cópias
} localizadas não informam suas datas. 
SEIXAS, F. F. Paradise Lost em português

de Gustave Doré - prática, aliás, comum mesmo em edições populares -; a partir do século XIX, recebe estudo de Xavier da Cunha (Lisboa: David Corazzi, 1884), reproduzido em algumas de suas reedições brasileiras; também há edições com estudo de Irene Truninger de Albuquerque (Lisboa: Verbo, 1983). A edição pela Martin Claret menciona A. H. Robertson como seu prefaciador; o catálogo da FBN o desconhece; o da BNP o reconhece como coautor de Human rights in Europe, juntamente com J. G. Merrills, em tradução de J oana Chaves (Lisboa: Piaget 2003).

\subsubsection{Tradução por Fernando da Costa Soares ( $\star 1937)$ e Raul Domingos Mateus da Silva $(\star 1936)^{13}$}

1. 2002. O Paraíso Perdido (trad. prefácio e notas). Lisboa: Chaves Ferreira.

Trata-se da segunda tradução em prosa realizada em Portugal. Parece ser também a primeira obra dos tradutores; Raul Domingos Mateus publicou ainda o volume histórico Crónica de 2004 do reino de Portugal ([Évora]: AEAmbiguae 2005). Profissionalmente, ambos estavam relacionados ao Supremo Tribunal de Justiça de Portugal.

\subsubsection{Traduções por Daniel J onas $(\star 1973)^{14}$}

1. 2006. MILTON, J. Paraíso perdido (trad., intro. e notas), 2.ed. Lisboa: Cotovia.

2. 2008. HUYSMANS, J. K. Ao arrepio. Lisboa: Cotovia. (Original: HUYSMANS, J. K. [1848-907]. À rebours [1884]).

\footnotetext{
${ }^{13}$ Tradução atestada pela BNP; a obra de Raul Domingos Mateus também pela mesma fonte.

${ }^{14}$ Traduções atestadas pela BNP; a tese do autor e suas demais obras (exceto Sonótono) também pela mesma fonte. Sonótono é atestada pelo catálogo online da Editora Cotovia.
} 
3. 2008. SHAKESPEARE, W. O mercador de Veneza, 2.ed. Lisboa: Cotovia, 2008. (Original: SHAKESPEARE, W. [bat.1564-616]. The Merchant of Venice [1596-8]).

4. 2009. Pirandello, L. Seis personagens à procura de um autor. Lisboa: Cotovia, 2009. (Original: PIRANDelLo, L. [1867-936]. Sei personaggi in cerca d'autore [1921]).

Primeiro literato de formação a incorporar a lista de tradutores lusófonos de Milton, sua tradução de Paradise Lost é fruto de seu mestrado ${ }^{15}$. Dedicou-se mormente à poesia (0 corpo está com o rei. Porto: Associação de Estudantes da FLUP, 1997; Moça formosa, lençóis de veludo. [Porto]: Conselho Directivo do Teatro do Campo Alegre, 2002; Os fantasmas inquilinos. Lisboa: Cotovia, 2005; Sonótono. Lisboa: Cotovia: 2008), mas recentemente publicou também uma peça (Nenhures. Lisboa: Cotovia, 2008).

\section{2 Traduções brasileiras}

\subsubsection{Traduções por Conceição Garcia Sotto Maior (?? ${ }^{16}$}

1. 1943. Goethe, J. W. Afinidades eletivas. Rio de Janeiro: Pongetti. (Original: GoETHE, J. W. [1749-832]. Die Wahlverwandtschaften [1809]).

2. 1946. MILTON, J . O paraíso perdido. Rio de J aneiro: Borsoi.

3. 1989. Chateaubriand, F. R. de. Os Natchez. Rio de Janeiro: Ediouro. (Originais: CHATEAUBRIAND, François-René de [1768848]. Les Natchez [1827]).

As três traduções citadas compõem o único testemunho compreensível do labor tradutório (ou de qualquer outro) de Conceição Garcia Sotto Maior; uma busca por "Conceição Garcia Sotto Maior" nos mecanismos usuais de busca online retornará apenas três obscuras páginas do Diário Oficial da União entre abril e maio de 1942; pesquisar por "Conceição Sotto Maior" ou

\footnotetext{
${ }^{15}$ Coelho, D. J. S. Uma tradução anotada de 'Paradise Lost'. [tese]. Lisboa: , Fac. de Letras, Univ. de Lisboa, 2005.

${ }^{16}$ Traduções de Milton e Goethe atestadas pela FBN; a de Chateaubriand pelo catálogo da Estante Virtual. A FBN atesta para a tradução de Goethe a existência de um exemplar de 1948; o exemplar mais antigo listado é atestado pelo catálogo da Estante Virtual.
} 
SEIXAS, F. F. Paradise Lost em português

"Conceição G. Sotto Maior" nos retornará quase invariavelmente às traduções citadas - em especial, às de Milton e Goethe.

Apesar de não encontrar referência à tradução de Les Natchez anterior aos anos 1980, sinto-me inclinado a ubicá-la próxima às demais; as traduções creditadas a Sotto Maior conheceram reedições pela Ediouro nessa década - a cópia a que tenho acesso data daí, bem como a maior parte das citações em referências bibliográficas às quais a pesquisa por seu nome nos conduz. Dessa reedição, consta uma breve nota bibliográfica acerca de Milton, firmada "C.G.S.M.", bem como a seguinte nota:

\begin{abstract}
O Sr. Manoel Bandeira ofereceu à Academia, em nome da autora, uma tradução do "Paraíso Perdido", dizendo que "quem já leu no original a obra de Milton, sabe que traduzi-lo é tarefa de amedrontar um gigante. Mas a Sra. Conceição Sotto Maior não se amedrontou, e durante três anos batalhou com coragem e paciência nessa "selva selvagia" - a tradução em prosa excelente e vigorosa da obra-prima da epopeia (sic) religiosa. O trabalho honra a inteligência feminina brasileira, e é com desvanecimento que o transmito à Academia" (MILTON: s/d: 11).
\end{abstract}

Neste ponto, não nos é possível sequer atestar se as reedições contaram com a supervisão da tradutora, ou se houve variantes textuais; 0 afastado das datas, bem como a editora responsável pela reedição conhecida por lançamentos baratos e raramente datados - me levam a supor que não.

A tradução de Sotto Maior do épico miltoniano foi empreendida, como afirma a nota, em prosa. É correta (com um ou outro deslize menor) e segue, em boa parte, a sintaxe miltoniana, deslocando, porém, certos constituintes e restituindo alguns hipérbatos, zeugmas e elipses, de modo a tornar o texto mais compreensível e sintaticamente menos denso.

Parece, em linhas gerais, um trabalho consistente, embora talvez saia em certa medida ferida de uma armadilha estilística comum às adaptações em prosa de poesia narrativa, digamos, elevada: a dificuldade em se encontrar o tom grandiloquente conseguido pela combinação entre léxico raro, sintaxe especial e metro fixo. Em poesia épica, léxico e sintaxe são, em 
SEIXAS, F. F. Paradise Lost em português

certa medida, exigências do metro: grande variedade vocabular e elasticidade de construção são necessárias para modelar as ideias em padrões rítmicos regulares; por sua vez, o metro, ao sobrepor suas exigências prosódicas às da sintaxe, opera o milagre literário de naturalizar e tornar fluídas as construções raras resultantes de sua mesma exigência. Ao se eliminar um destes elementos, portanto, a pertinência dos demais fica comprometida.

No caso da tradução de Sotto Maior, é evidente seu esforço em manter os constituintes mais ou menos nas mesmas posições que se encontram no texto miltoniano, bem como o de manter um uso lexical condizente ao estilo épico. A sintaxe torcida da invocação inicial às musas - um dos trechos sintaticamente mais densos de todo o poema - permanece, na versão de Sotto Maior, praticamente inalterada; mesmo nos trechos onde Sotto Maior opera uma simplificação mais pesada do texto (as invocações às musas parecem progressivamente mais e mais transformadas do ponto de vista sintático), sua versão ainda não ousa pesadamente contra a construção miltoniana. Ocorre que seus motivos para manter os constituintes nessas posições não são os mesmos de Milton. Por outro lado, a fluidez que o metro confere a uma sintaxe carregada é perdida quando o texto é vertido em prosa: o tamanho das palavras se altera do inglês para o português, os procedimentos morfológicos de construção de sintagmas adjetivais também e os sinais de pontuação se convertem em marcas prosódicas não desautorizadas por exigências métricas. Consequentemente, o texto de Sotto Maior corre o risco de soar quebrado onde Milton soa fluido - apesar de seu texto soar inteligível onde o dele corre o risco de parecer obscuro (e devemos ter em mente que algumas obscuridade seriam, sim, intencionais). São armadilhas, como disse, naturais a esse tipo de empreendimento; são consistentes com uma tradução cujo objetivo parece ser dar a conhecer o conteúdo do texto de Milton, mantendo, ao menos tempo, alguma lembrança do estilo grandioso apropriado à épica. 
SEIXAS, F. F. Paradise Lost em português

\subsubsection{Traduções por Paulo Matos Peixoto (?? ${ }^{17}$}

1. 1989. Lívio, T. História de Roma (trad. e notas), 06 vols. São Paulo: Paumape. (Original: Lívio, T [Titus Livius] [59 a.C.-17 d. C. ]. Ad Urbe Condita Libri [27-52 a.C. ]).

2. 1995. MILTON, J. Paraíso perdido (trad. e intro.). São Paulo: Paumape, 1995.

A história autoral de Paulo Matos Peixoto é derivada em parte de sua história editorial. As duas únicas traduções que the são creditadas foram publicadas por sua própria editora. (Note-se que o nome desta é composto pelas sílabas iniciais do nome do tradutor. Inicialmente chamada Matos Peixoto, passou mais tarde a Paumape e, mais recentemente, Germape possivelmente as iniciais de sua esposa, Gertrud Matos Peixoto ${ }^{18}$. Para nossos interesses atuais, pouco interessa se trata-se da mesma editora ou de editoras diferentes; todas estão associadas ao nome de Matos Peixoto - que figura em inúmeras obras de seus catálogos sob variadas denominações autorais).

Como autor, Matos Peixoto é historiador. Parece haver se fixado em história política e militar; sob sua autoria direta, encontramos Caxias: nume tutelar da nacionalidade (02 vols. Edico: 1973), Atentados políticos: de César a Kennedy (PAUMAPE: 1988), Anibal, o pai da estratégia (PAUMAPE: 1991) e, fugindo à tendência das anteriores, Virgem Maria, mãe de Deus (GeRMAPE: 2003). Como prefaciador, escreveu introduções a inúmeras "adaptações" constantes do catálogo da Paumape: obras de Homero, Virgílio, Molière, dos tragediógrafos gregos, as adaptações do casal Lamb das peças de Shakespeare, entre outras. Também é creditado pela revisão de duas

17 Traduções atestadas pelo catálogo do Estante Virtual, a de Tito Lívio em mais de uma edição. Demais obras também atestadas pela mesma fonte; da extensa bibliografia de Matos Peixoto atestada por livrarias virtuais - estando inclusive algumas obras ainda disponíveis -, FBN conta apenas seis obras.

${ }^{18}$ Esta conjetura pertence a Denise Bottmann, autora de Não gosto de plágio: um blog contra plágios de tradução e variedades várias, 〈http:// naogostodeplagio.blogspot.com/ >, em sua entrada de $08 / \mathrm{dez} / 2009$, intitulada "da paulo matos a cedic". Seria pertinente mencionar que, segundo as investigações conduzidas por Bottmann e que constituem o cerne de seu blog, algumas traduções publicadas por Matos Peixoto/ Paumape/Germape e posteriormente reeditadas pela Cedic seriam, de fato, plágios de traduções portuguesas; a autora comprova com imagens digitalizadas das referidas edições. Não parece ser o caso da de Milton. 
SEIXAS, F. F. Paradise Lost em português

traduções sem tradutor identificado (KEMPIS, T. Imitação de Cristo. Paumape: 1979; LA FontAInE. Fábulas [intro e rev.trad.], 1993). Na qualidade de editor da Paumape, coordenou a elaboração de inúmeros dicionários técnicos, em especial da área do direito.

Sua tradução de Paradise Lost, para a qual também escreve uma introdução e à qual agrega um pequeno glossário, pode talvez ser contada entre as "adaptações" editadas pela Paumape; seu texto difere consideravelmente do de Milton. Inúmeras passagens são suprimidas: o poema de Milton conta com quatro invocações às musas - em uma das quais faz declaração pessoal de sua cegueira e dos tempos difíceis pelos quais passa -; a versão de Matos Peixoto independe de auxílio divino por completo. Ademais, todo o resto é condensado com supressão aparentemente aleatória de elementos, quando não descaracterizado pelo acréscimo ou alteração de ideias.

Do ponto de vista do "estilo elevado", a tradução tampouco alcança acordo consigo mesma. Por um lado, serve-se de termos eruditos e utiliza as elegantes segundas pessoas da gramática tradicional (tu e vós, conjugadas como se aprende na escola); não se exime, porém, de expressões populares inadequadas ao épico. 0 texto de Milton é estilisticamente bastante homogêneo: suas variações não chamam demasiada atenção a si mesmas, tampouco - pela matéria mesma com que trabalha, mas também por algumas de suas convicções - se entrega a níveis populares e grosseiros de escrita: ao falar de relações sexuais e nudez (IV.733-75, V.350-7, VIII.510-20; pp.98-9, 115-6, 191-2, respectivamente, da edição de Gordon Teskey [2005]), e mesmo ao sugerir assuntos como a excreção no Éden pré-queda (V.03-8; p.106 da edição de Teskey [2005]), sua poesia é decorosa e se exime de gracejos. Em situação semelhante, os charmes de Shakespeare e de Chaucer seriam outros. Assim, personagens que "dão pulos de alegria" (1995, p.30) não fariam normalmente parte de seu universo de emoções fortes, porém, sempre muito sóbrias e arrazoadas.

A grande armadilha da "adaptação" reside no fato de que não é tarefa menos complexa que traduzir em sentido estrito. Tanto para traduzir quanto 
SEIXAS, F. F. Paradise Lost em português

para adaptar são necessários grande conhecimento do original e uma análise formal que faculte o estabelecimento de parâmetros de adaptação: o que manter, o que mudar, como mudar, por que mudar. Onde a tradução de Sotto Maior é consistente (mesmo em suas limitações), demonstra certo tipo de intenção tradutória; a de Matos Peixoto, inconstante no léxico, no registro e na seleção de supressões, não deixa entrever semelhante plano. Sua adaptação é ruim por ser "livre" no mau sentido: livre de planejamento.

\section{Considerações finais}

A traj etória de Paradise Lost em língua portuguesa conheceu sucessos e insucessos. Pouco mais de um século após sua edição definitiva, recebeu a primeira versão portuguesa; desde então, foi acrescido de inúmeras outras a intervalos regulares - em média, uma tradução nova a cada 31 anos entre 1789 e 2006. Apesar da difusão e do prestígio crítico de que parecem haver gozado algumas, essas traduções tendem a desaparecer relativamente rápido do mercado editorial. No Brasil, a única tradução ainda em catálogo é a de Lima Leitão, como já mencionado; as traduções portuguesas mais recentes não tiveram circulação por aqui, tampouco parecem atualmente disponíveis em Portugal.

Por um lado, poderíamos nos perguntar por que o épico de Milton parece despertar interesse regular, porém, não exatamente duradouro no público lusófono. Se compararmos sua sorte à de outros clássicos - as traduções do teatro grego ateniense, por exemplo -, veremos que obras bem mais antigas despertam uma curiosidade que fomenta a coexistência de várias traduções disponíveis para as mesmas obras. Por outro, essa incursão pelas traduções de Milton nos releva algo de nossa própria história editorial abundante em editoras transientes, apostando em edições populares de textos já consagrados e em reedições tanto de obras nacionais quanto de traduções antigas, já desgarradas dos detentores de seus direitos autorais. Enquanto as editoras brasileiras brincam de passa-anel com a tradução de Lima Leitão - a 
SEIXAS, F. F. Paradise Lost em português

única portuguesa a entrar em nosso sistema editorial -, pergunto-me se é por sua qualidade (acerca da qual não lanço dúvidas) que é aqui tão reeditada.

\section{Referências bibliográficas}

\section{1 Edições de 'Paradise Lost' e suas traduções}

Milton, J.; Teskey, G. (ed.). Paradise Lost: a Norton critical edition. Nova lorque/ Londres: Norton, 2005.

MiLton, J. O paraíso perdido (trad. António José de Lima Leitão; prefácio Xavier da Cunha). Empresa Literária Universal: Lisboa, 1938.

MILTon, J . O paraíso perdido (trad. Conceição G. Sotto Maior). Ediouro, 1985.

Milton, J. O paraíso perdido (trad. e intro. Paulo Matos Peixoto). São Paulo: Paumape, 1995.

MiLton, J. O paraíso perdido: poema épico (trad. e comentários Francisco Bento Maria Targini). Paris: Typ. Firmino Didot, 1923, 02 vols.

MiLton, J. Paraíso perdido (trad. António J osé de Lima Leitão; prefácio A. H. Robertson). São Paulo: Martin Claret, 2006.

\section{2 Referências teóricas}

Addison, J.; ARBER, E. (ed.). Criticism on Milton's Paradise Lost from 'The Spectator', 31 December, 1711-3 May, 1712. Southgate, London: English Reprints, 1868.

BASTOS DA SILVA, J. M. Milton e Pope em Portugal (séculos XVIII e XIX): as traduções de F. B. M. Targini e o contexto da crítica. In: Cadernos de Tradução, vol. 01, n. 05. Florianópolis: Núcleo de Tradução, 2000/1. pp. 109-32.

Moser, F. M. As traduções de Milton do Padre J osé Amaro da Silva. Guimarães: Congresso Histórico de Guimarães e sua Colegiada, 1981. P. 32-7.

SALGADO, A. J . António J osé Lima Leitão (1787-1856): médico, escritor e maçon (obra e posicionamento político). In: SILVA, F. R.; CRUZ, M. A.; RIBelRo, J. M.; Osswald, H. (orgs.). Estudos em homenagem a Luis António de Oliveira Ramos, 03 vols. Porto: FLUP, 2004. Vol. 03, pp. 941-7. 
SEIXAS, F. F. Paradise Lost em português

Verbete "São Lourenço (Francisco Bento Maria Targini, barão e visconde de)". In: Portugal: dicionário histórico. «ttp:// www. arqnet.pt/ dicionario/ saolourencobv. html>

\section{3 Bases de dados}

Biblioteca Nacional de Portugal. «http:// www. bnportugal.pt/> Estante Virtual. «http:// www.estantevirtual.com. br/> Fundação Biblioteca Nacional. 〈http:// www.bn.br/portal/> Index Translationum: World Bibliography of Translation. «ttp:// portal. unesco.org/ culture/ en/ ev. phpURL_ID $=7810 \& U R L \_D O=D O \quad T O P I C \& U R L \_S E C T I O N=201 . \mathrm{html}>$ Livros Cotovia. «ttp:// www.livroscotovia.pt> 